\title{
Physical Education Teaching Assistant Perceptions on Classroom Management and Teaching Effectiveness
}

\author{
Minhyun Kim and Mike Stocz \\ Department of Health Exercise Sports and Sciences, University of New Mexico, Albuquerque, New Mexico 87131, NM, USA
}

\begin{abstract}
This research examined graduate students in physical education TA (teaching assistant) positions instructing lower level classes, and how classroom management skills prior to student teaching may improve the quality of TA classroom instruction. A survey was conducted with TA graduate students instructing lower level classes and an examination of their opinions and open mindedness as to the idea of education in leadership methods and class management to improve the quality of TA instruction. The following questions were examined in the survey: comparative importance between classroom management and mastery of skills, having detailed knowledge of a subject to teach entry level classes in this subject or having leadership capabilities to successfully manage the class, and knowledge level of the subjects they are teaching. This study revealed that most TAs believe that knowing and developing classroom management skills can help enhance their efficiency of content delivery for students. Thus, it is imperative for colleges and universities to seek highly qualified individuals with TA positions while providing training to improve their classroom management and leadership skills. The authors offer suggestions for development of TAs further.
\end{abstract}

Key words: Physical education teaching assistant, classroom management, teaching effectiveness.

\section{Introduction}

Teaching assistants have traditionally helped with classroom instruction, through one-on-one counseling with students, class set-up, and content development. Over time, teaching assistants have taken a greater role in teaching and managing students, as evidenced by teaching assistants leading an after school program [1]. Teaching assistants are serving a greater role in the classroom by frequently being listed as the instructor of record for many physical education classes [2]. Effective teaching is the greatest indicator for academic success, and with $57.7 \%$ of teaching assistants reporting that they wanted to be a professor at a college or university [3], developing solid teaching skills in current teaching assistants can have a long lasting effect for future educators.

But what exactly makes a teacher effective? The purpose of this research was to begin exploring the answer to this question through the eyes of current

Corresponding author: Minhyun Kim, Ph.D. candidate, graduate assistant, research field: leadership in physical education. E-mail: mhkim@unm.edu. teaching assistants. A scholar similarly examined teaching assistants in regards to the training they received previous to employment, development through their host institution, and why these individuals chose to be teaching assistants [3]. Previous literature also suggests that classroom management directly impacts student's learning progress, especially with low-performing students, those in special education, and within ethnic minorities [4]. Classroom management can be defined as "those activities of classroom teachers that create a positive classroom climate within which effective teaching and learning can occur" [5]. Without initial group management in place, teachers have a difficult time keeping learner attention [6]. In order for teachers to effectively manage the class, the following should be considered: actively supervising students, implementing rigorous classroom rules and routines, using behavior reduction strategies, structuring the classroom environment, and learning techniques to decrease inappropriate behavior [7]. By acquiring and learning classroom management skills, teachers are 
able to contribute positive educational outcomes [8].

The primary roles of teaching assistants are to support instruction, which may include teaching classes, developing academic and/or instructional materials, and assessment of students. A majority of this study centered around Martin and Sugarman's ideas on classroom management by measuring the perceived level of importance of leadership and group management skills for Teaching Assistants (hereby referred to as TAs or TA) through a survey methodology [5]. This study will further the works of Russell and Jago et al. in determining how teaching assistants perceive classroom management skills in terms of importance, further previous research on TA experiences prior to employment, and further emphasize the importance of teaching assistant development [2].

\section{Method}

This study was conducted at a major southwest university in the United States involving TAs, primarily involving physical education classes. A survey was created questioning the idea of how education in leadership methods and group management prior to student teaching may improve the quality of TA classroom instruction. The participants were graduate students of a major southwest university from various departments (curriculum and instruction, sport administration, and exercise science). The survey focused on previous experience and training in leadership, self-confidence in leading class, leadership application to the classroom environment and how these TAs would respond to additional opportunities to learn leadership skills.

Due to the lack of previous research dealing with TA teaching skills, instructions and motivations to improve their teaching quality, the authors created a survey based on previous experiences. This survey was then assessed by a prominent academic in the field of curriculum and instruction within physical education before it was administered. The revised survey was then administered to 27 TAs within the physical education department at a major southwest university in fall 2012.

This survey was used to determine what TAs considered the most important factors for teaching a physical education class, including previous experiences with the subject matter and leadership, emphasis on class management or knowledge, and if they would be willing to improve their teaching quality through training in a classroom setting. These question themes were chosen to assess the areas of physical education knowledge, classroom management, and dedication to improvement. This survey was prepared to be exploratory and to be built upon in future research.

\section{Results}

The survey began by asking about the experience level of TAs at this study's location. 14 respondents said they had previous experience directly related to the classes they were teaching, 9 claimed they had some experience with the activity they were teaching, 3 said they had little experience, and 1 did not have any previous experience. When distributed, the administrators left the options open to the respondents' interpretations of the results (Fig. 1). Many TAs have previous experience with what they are teaching as a participant, thus the authors interpret the little-to-no experience responses as they had not previously been deeply involved with the activity itself. It was reported at this study's location that many new TAs were left to teach what more experienced TAs did not want to teach. Typically, these TAs were given a period of time to learn the activity, materials for the activity, and help from more experienced TAs.

The second question on the survey sought to examine what TAs believed was more important in a classroom setting-leadership and management or detailed knowledge with a both option also available. 8 respondents selected leadership and management, 4 respondents chose that detailed knowledge was most 


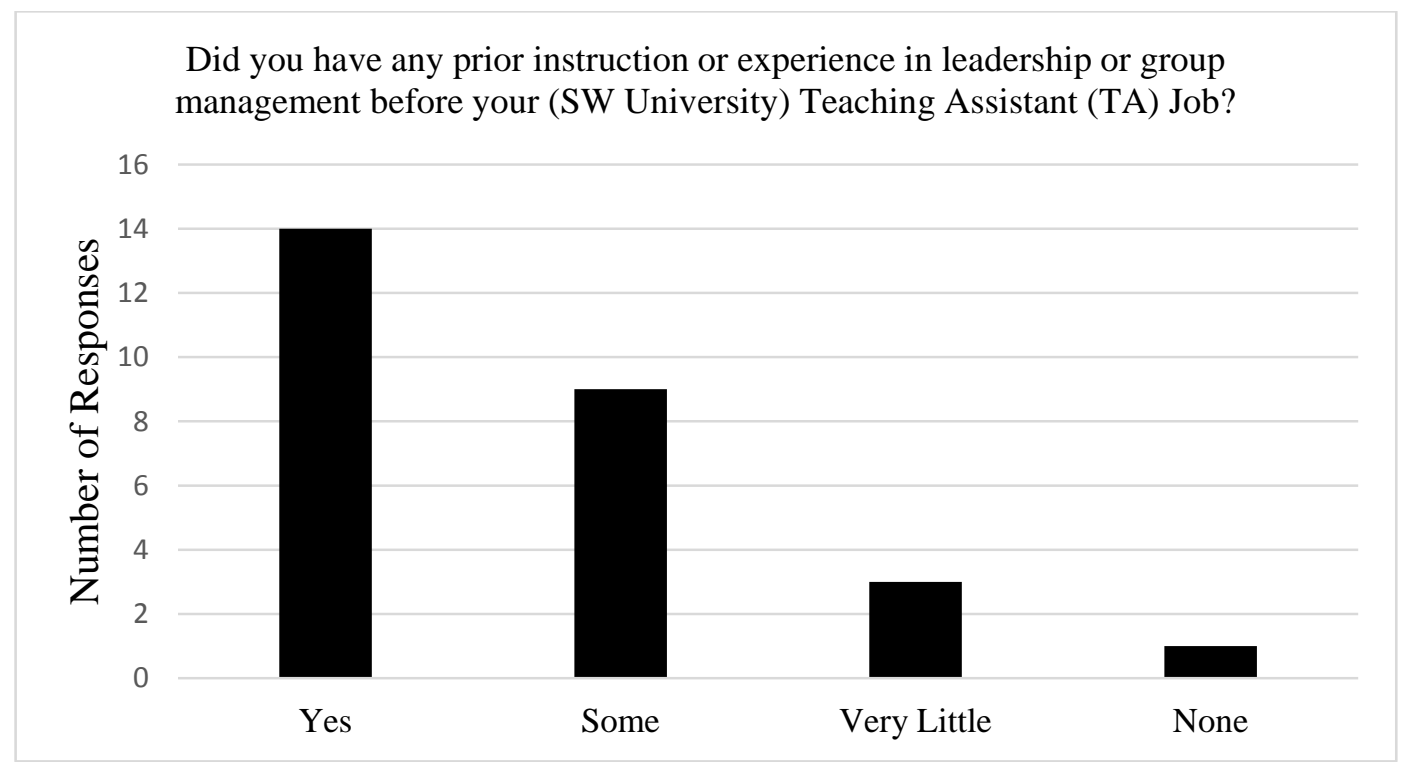

Fig. 1 Reported previous experience levels.

Which do you believe is most important

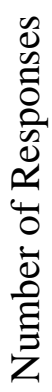
in the structure of physical activity classes?

Fig. 2 Preferred classroom structure.

important, and with the both option receiving 15 votes (Fig. 2). Detailed knowledge would include, for this survey, knowledge of professional and amateur sport contest results, pros and cons in current teaching trends via online media boards, or insider information within a sport's higher competitive amateur or professional leagues. Classroom leadership and management involved aspects of lesson planning, classroom control, syllabi development, assigning and grading assignments, and overall course progression.

These responses were not surprising to the authors, but would suggest that a small percentage of TAs in the examined physical education department emphasized leadership and management of a classroom over detailed knowledge of the sport. It should be stated that all physical educators need to have in-depth knowledge of the flow of the physical activities being taught, including all safety precautions to prevent injury. Physical educators will not only put their students in harm's way if they do not understand the activity itself, but could lead to legal ramifications for the educator and the entity this educator represents in teaching this activity.

The third question asked how significant a TAs leadership and group management skills were to effectively teach a class. 19 responded that these skills 
were significant, 6 responded somewhat significant, 1 responded very little significance, and 1 responded that these skills were not significant at all to effective teaching (Fig. 3). These results are telling in that TAs identify that leadership and group management skills are needed to successfully teach a class.

The last question asked TAs if they believed a leadership seminar class would help their teaching performance. 15 responded that it would be beneficial, 9 responded that it would be somewhat beneficial, 2 responded that the class would do very little for their teaching performance, and 1 responded that this class would in no way aid their teaching performance (Fig. 4). According to a survey of TAs compiled by Prieto and Scheel, many TAs were dissatisfied with the level of training they receieved on the job. Thus, based on the survey results, it is recommended that employers of TAs provide a seminar or training opportunity that helps TAs enhance their class management and leadership skills [9].

\section{Discussion}

Many professors claimed to have significant teaching experience, and that this experience comes from their involvement as a TA during graduate school [9]. Many other instructors within the education system may also have experience as a TA, thus more attention must be paid academically to help develop TAs. This study aided in this conquest by identifying what current TAs believe are the most

Do you consider leadership and group management skills siginifcant in effectively teaching your class?

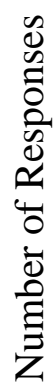

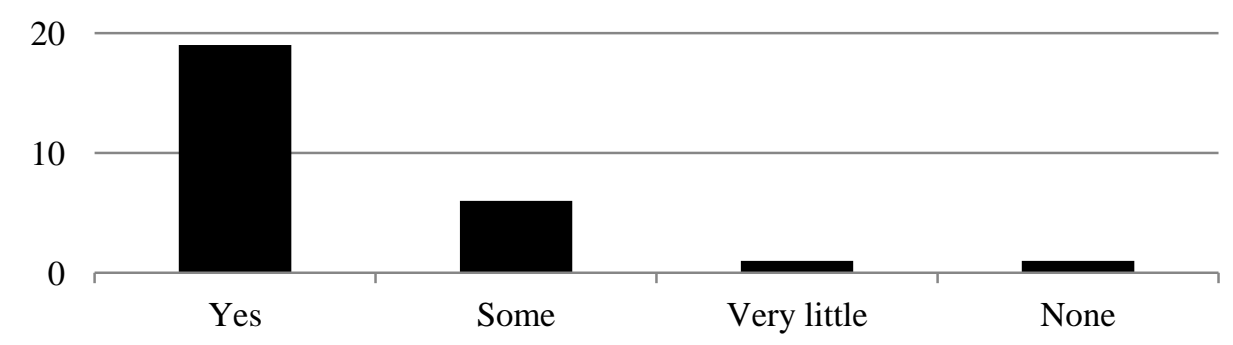

Fig. 3 Management Skills Assessment.

Do you think a group leadership seminar would be effective in improving your teaching performance?

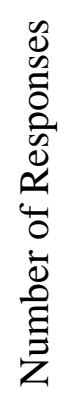

20

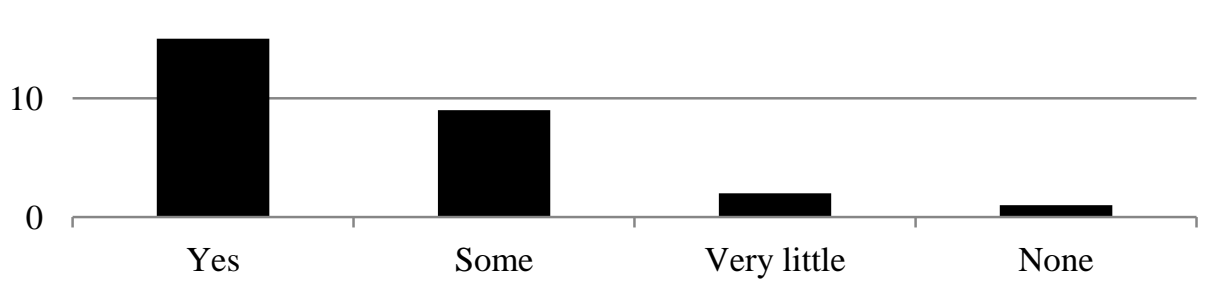

Fig. 4 Professional Development Course. 
effective means of teaching. In particular, because physical education class in college and university is frequently being held a gymnasium where environments are typically less structured and open places, effective class management is required for TAs along with content knowledge. In fact, classroom management is considered one of the most difficult skills for instructors to master. Without gaining knowledge and numerous teaching experiences, TAs (and eventually instructors and/or professors) may experience situations which would hinder their instruction, thus lessening the effects of their lesson plans.

Some researchers conceptualize leadership as a trait or behavior, whereas other view leadership from an information-processing perspective or relational standpoint [10]. Northouse theorizes leadership as "a process of influencing groups towards common goals"; therefore, it stands to reason that increasing leadership skills should improve classroom management and teaching effectiveness. From observations throughout the authors' time as TAs or leading TAs, they found that many TAs leading lower level classes often mastered the subject matter being taught, but were lacking in management skills necessary to control the classroom. This resulted in a lack of effective communication, safety management, and class assessment from their peers (due to the peer reviewers often having a lack of classroom management skills themselves). These TAs did realize through the survey that classroom management skills were important to their craft, thus suggesting that they would be interested in seeking further help to improve their teaching style. Thus, a training program was conceptualized for this university's TAs to help hone these skills. These findings suggest that detailed knowledge of a subject is required to teach an entry level course may take a backseat to the scheme of having the necessary skills to first capture the attention of your audience, and then impart the knowledge to attentive listeners.
TA research has grown as of late, but more work needs to be done in this area. Specific to physical education, researchers should begin to conceptualize more efficient training programs for TAs; this could include a survey of academics who were TAs at one point. A survey of students is typical after an instructor's class near the end of the semester, but often these surveys are examined by the instructor and a delegate from that host college only. Discovering a department's weaknesses in terms of TA teaching styles also would prove beneficial in identifying not only what the instructor can improve on, but also what a department should train their TAs to teach. TAs do not feel adequately trained, and the results of this study suggest the same, but specifically to classroom management [1]. Future research could explore this idea more in-depth by measuring teaching effectiveness of TAs who are taking a course in classroom management as opposed to a control group who receives only basic training to be a TA. Lastly, TA research should begin to examine high school TAs to determine how effective TAs are in those settings.

\section{Implications}

It is necessary for universities and colleges to diligently hire qualified TAs to better protect themselves legally and provide quality programs for their students. This study found that TAs realize that classroom management is essential for having a successful class, although many have fallen short in executing classroom management skills. Thus, TAs should seek the best opportunity for developing classroom management skills and leadership skills. Additionally, the authors suggest that universities and colleges have some types of development plans or training opportunities in place for their new and current TAs. A seminar class, which was suggested through this study, although a mentorship program also would have its benefits in development of TAs. In addition, a peer-review system would also be beneficial for TAs [9]. 


\section{Limitations}

As with all research, this study was conducted with some limitations. First, there is a severe lack of research surrounding the area of teaching assistants within physical education. This limited the researchers' access to previously used survey methods, thus this survey should be a starting point for future research. Next, the researchers only received feedback from one university for this study. This may be for a multitude of reasons, but future research should try to encompass a variety of universities in their studies from various locations. Finally, this research only dealt with physical education TAs, and thus these results may not apply to other concentrations.

\section{Conclusion}

Research with TAs is very limited within the realm of physical education. In fact, research has primarily been conducted within college TAs or TAs for elementary school aged students. Many TAs are in charge of lower level classes, including physical education classes in universities and colleges. Their roles have major impact on the quality of these classes and students' learning. Teaching physical education classes at the college level requires a high level of professionalism, which includes content knowledge, classroom management skills, and leadership. This study revealed that most TAs perceive that knowing and developing classroom management skills can help enhance their efficiency of content delivery for students. Thus, it is imperative for colleges and universities to seek highly qualified individuals with TA positions while providing training to improve their classroom management and leadership skills; this could be offered through a seminar or mentorship opportunity. Universities may ask their professors to aid in the development of TAs as many professors were TAs when they were in school. A hands-on approach can be taken to improve teaching quality for
TAs, and having incoming TAs examine current TA classes may prove beneficial. To build on this point, incoming TAs could serve as substitute teachers to give an observer the opportunity to examine this TAs strengths and weaknesses.

\section{References}

[1] Jago, R., Sebire, S., Davies, B., Wood, L., Edwards, M., Banfield, K., Fox, K., Thompson, J., Powell, J., and Montgomery, A. 2014. "Randomised Feasibility Trial of a Teaching Assistant Led Extracurricular Physical Activity Intervention for 9 to 11 Year Olds: Action 3:30." International Journal of Behavioral Nutrition and Physical Activity 11 (114): 65-91.

[2] Wright, S. P., Horn, S. P., and Sanders, W. L. 1997. "Teacher and Classroom Context Effects on Student Achievement: Implications for Teacher Evaluation." Journal of Personnel Evaluation in Education 11: 57-67.

[3] Russell, J. A. 2009. "A Survey of Basic Instructional Program Graduate Teaching Assistant Development and Support Processes." Research Quarterly for Exercise and Sport 80 (4): 792-5.

[4] Saphier, J., and Gower, R. 1997. The Skillful Teacher: Building Your Teaching Skills. Carlisle, MA: Research for Better Teaching, Inc..

[5] Martin, J. and Sugarman, J. 1993. Models of Classroom Management. (Second Edition). Bellingham, Washington: Temeron Books Inc.

[6] Ingersoll, R. M., and Smith, T. M. 2003. "The Wrong Solution to the Teacher Shortage." Educational Leadership 60 (8): 30-3.

[7] Oliver, R. M., and Reschly, D. J. 2007. Effective Classroom Management: Teacher Preparation and Professional Development. TQ Connection Issue Paper on Improving Student Outcomes in General and Special Education. Washington: National Comprehensive Centre for Teacher Quality. Accessed April 14, 2015, http://www.tqsource.org/topics/effectiveClassroomMana gement.pdf.

[8] Baker, P. H. 2015. "Managing Student Behavior: How Ready Are Teachers to Meet the Challenge?" American Secondary Education 33 (3): 51-64.

[9] Prieto, L. R., and Scheel, K. R. 2008. "Teaching Assistant Training in Counseling Psychology." Counselling Psychology Quarterly 21 (1): 49-59.

[10] Northhouse, P. G. 2013. Leadership Theory and Practice (6th ed.). California, CA: Sage. 